Research article

\title{
A common fungicide impairs stream ecosystem functioning through effects on aquatic hyphomycetes and detritivorous caddisflies
}

\author{
Aydeé Cornejo $^{\mathrm{a}, \mathrm{b},{ }^{*}, 1}$, Javier Pérez ${ }^{\mathrm{c}, 1}$, Alberto Alonso ${ }^{\mathrm{c}, 1}$, Naiara López-Rojo ${ }^{\mathrm{c}}$, Silvia Monroy ${ }^{\mathrm{c}}$, \\ Luz Boyero ${ }^{\mathrm{c}, \mathrm{d}}$ \\ ${ }^{a}$ Freshwater Macroinvertebrate Laboratory. Zoological Collection Dr. Eustorgio Mendez, Gorgas Memorial Institute for Health Studies (COZEM-ICGES), Ave. Justo \\ Arosemena and Calle 35, 0816-02593, Panama City, Panama \\ b Doctoral Program in Natural Sciences with emphasis in Entomology, University of Panama, Panama City, Panama \\ ${ }^{\mathrm{c}}$ Department of Plant Biology and Ecology, Faculty of Science and Technology, University of the Basque Country (UPV/EHU), Leioa, Spain \\ d IKERBASQUE, Bilbao, Spain
}

\section{A R T I C L E I N F O}

\section{Keywords:}

Litter decomposition

Chlorothalonil

Aquatic hyphomycetes

Detritivores

Plant diversity

\begin{abstract}
A B S T R A C T
Fungicides can reach streams through runoff or adhered to leaf litter, and have the potential to adversely affect processes such as litter decomposition and associated communities. This study investigated the effects of chlorothalonil, a widely used fungicide, on litter decomposition, detritivorous invertebrates (larvae of the insect Sericostoma pyrenaicum) and aquatic hyphomycetes (AHs), using stream microcosms. We considered the single and combined effects of two exposure modes: waterborne fungicide (at two concentrations: $0.125 \mu \mathrm{g} \mathrm{L}{ }^{-1}$ and $1.25 \mu \mathrm{g} \mathrm{L}^{-1}$ ) and litter previously sprayed with the fungicide (i.e., pre-treated litter, using the application dose concentration of $1250 \mu \mathrm{g} \mathrm{L}^{-1}$ ). We also assessed whether fungicide effects on invertebrates, AHs and decomposition varied among litter types (i.e., different plant species), and whether plant diversity mitigated any of those effects. Invertebrate survival and $\mathrm{AH}$ sporulation rate and taxon richness were strongly reduced by most combinations of fungicide exposure modes; however, invertebrates were not affected by the low waterborne concentration, whereas AHs suffered the highest reduction at this concentration. Total decomposition was slowed down by both exposure modes, and microbial decomposition was reduced by litter pre-treatment, while the waterborne fungicide had different effects depending on plant species. In general, with the exception of microbial decomposition, responses varied little among litter types. Moreover, and contrary to our expectation, plant diversity did not modulate the fungicide effects. Our results highlight the severity of fungicide inputs to streams through effects on invertebrate and microbial communities and ecosystem functioning, even in streams with well-preserved, diverse riparian vegetation.
\end{abstract}

\section{Introduction}

Most headwater streams flowing through forested areas are detritusbased ecosystems, which rely on allochthonous inputs of terrestrial plant litter as their basal resource (Wallace et al., 1997). Riparian vegetation produces shading that limits within-stream primary production and, at the same time, provides leaf litter (hereafter litter) (Vannote et al., 1980) that is decomposed by microorganisms - mostly aquatic hyphomycetes (AHs; Bärlocher, 1985) - and detritivorous invertebrates (Graça, 2001). AHs increase resource quality for invertebrates through an increase in litter nutrient content and the degradation of recalcitrant components. They thus enhance consumption by invertebrates, ultimately providing food for predators (Wallace et al., 1997). The process of litter decomposition is thus a key component of stream ecosystem functioning, and is often used as indicator of stream ecosystem integrity (Gessner and Chauvet, 2002).

Given the importance of decomposition in streams, how it is influenced by human-related impacts has become a widespread focus of research (Boyero et al., 2012; Woodward et al., 2012; Martínez et al., 2014; Arroita et al., 2015). One human activity with known

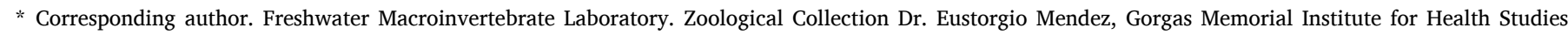
(COZEM-ICGES), Ave. Justo Arosemena and Calle 35, 0816-02593, Panama City, Panama.

E-mail address: acornejo@gorgas.gob.pa (A. Cornejo).

1 These authors equally contributed to this work.
} 
consequences on decomposition within streams is the use of fungicides in agriculture or forestry (Artigas et al., 2012; Flores et al., 2014a; Zubrod et al., 2015a). Fungicides can reach streams through several pathways (Newton et al., 2018), including runoff (Berenzen et al., 2005) and adhered to leaves of treated plants that may subsequently enter the stream (e.g., riparian plants can be sprayed with fungicides accidentally when they border agricultural or forestry areas) (Zubrod et al., 2015b).

Streams flowing through catchments subjected to fungicides have reduced microbial decomposition rates compared to control streams (Rasmussen et al., 2012b; Fernandez et al., 2015). Similarly, microbial decomposition, fungal diversity and biomass are altered by fungicides in laboratory conditions (Rasmussen et al., 2012a; Zubrod et al., 2015a; Gardeström et al., 2016). Invertebrates can be negatively affected by waterborne fungicides, or by feeding on litter previously exposed to fungicides, showing reduced feeding and growth rates (Dimitrov et al., 2014; Zubrod et al., 2015b; Gardeström et al., 2016) and increased mortality (Zubrod et al., 2014; but see Newton et al., 2018). However, relevant experiments have been conducted mostly with crustaceans (Gammarus fossarum Koch and, to a lesser extent, G. pulex L. and Asellus aquaticus L.), whereas detritivorous insects are an overlooked group in assessments of fungicide effects. This is noteworthy because insects usually dominate the detritivore guild in streams around the world (Boyero et al., 2011), and their flying adults can transfer effects to terrestrial ecosystems (Konschak et al., 2019).

Another limitation of most existing experiments is the use of litter from a single species (black alder), which limits extrapolations to realworld situations. Even if black alder is often a dominant riparian species across Europe, litter in streams is usually a mixture of species that can differ in terms of fungicide adherence and their subsequent toxicity. Moreover, it is possible that the diversity of resources provided by litter mixtures enhances decomposition (Tonin et al., 2017; López-Rojo et al., 2018, 2019) and microbial decomposer diversity (Kominoski et al., 2010). Thus, litter diversity could compensate for the negative effects of fungicides on decomposition, as observed for other stressors (Duarte et al., 2008).

We addressed research gaps in a microcosm experiment, where we examined the effects of chlorothalonil (a common fungicide in agriculture and forestry worldwide; e.g., Du Gas et al., 2017; Cornejo et al., 2019) on microbial and invertebrate-mediated decomposition of litter of several riparian plant species, individually and mixed. We used a common detritivorous caddisfly and quantified its survival and growth, and we determined $\mathrm{AH}$ sporulation rate, taxon richness and assemblage composition, in response to (1) litter pre-treated with the fungicide, (2) waterborne fungicide, and (3) both exposure modes simultaneously. We explored which of these exposure modes had the greatest effects and whether their effects were additive, synergistic or antagonistic (Jackson et al., 2016). We tested the following hypotheses:

(1) Litter pre-treatment with the fungicide removes fungal hyphae that had penetrated the leaf tissue (endophytic fungi, terrestrial saprotrophs and AHs; Seena and Monroy, 2016), resulting in altered leaf structure; this increases the leaching of soluble compounds (mostly nutrients) and hence reduces litter quality.

(2) Litter pre-treatment with the fungicide negatively affects (i) $\mathrm{AH}$ sporulation rate, taxon richness and assemblage structure, as fungi are the target of fungicides; (ii) invertebrate survival and growth, given that detritivorous invertebrates largely depend on the microorganisms colonizing litter (Graça, 2001); and (iii) litter decomposition mediated by microorganisms and invertebrates, because of the above-mentioned effects on both types of organisms.

(3) The waterborne fungicide has similar negative effects to those described in hypothesis 2 .

(4) Both exposure modes acting simultaneously have additive effects (i.e., their combined effects are the sum of both effects).
(5) Fungicide effects on AHs, invertebrates and decomposition have the same direction, but vary in strength, in the presence of different litter types (i.e., litter from different plant species, which differ in quality). Effects are lower in higher-quality litter because it provides better resources (e.g., more nutrients) and thus increases assemblage resistance and resilience to the fungicide (Allison and Martiny, 2008).

(6) Fungicide effects are lessened in the presence of litter mixtures compared to single litter types, because they provide better resources, either through complementarity (i.e., different litter types provide different resources) or selection (i.e., the higher probability that a particularly high-quality litter type is present) (Tonin et al., 2017).

\section{Materials and methods}

\subsection{Fungicide}

We obtained the chlorothalonil, commercialised as DACONIL 50SC (Comercial Química Massó S.A, Barcelona, Spain), in November 2018. Chlorothalonil is a polychlorinated aromatic compound $\left(\mathrm{C}_{8} \mathrm{Cl}_{4} \mathrm{~N}_{2}\right.$, $2,4,5,6$ - tetrachloroisopthalonitrile) that acts as a potent and broadspectrum pesticide, being thus widely used in multiple practices such as agriculture (Chen et al., 2001), forestry (Du Gas et al., 2017), golf turf maintenance (Sigler and Turco, 2002) or growing of ornamental plants (Mueller et al., 2005). According to the US Geological Survey, in 2016 (the most recent year with available information), about 5000 metric tons of chlorothalonil were used in the United States (https://water. usgs.gov/). While its use in Europe has recently been prohibited (01/04/2019; Europe Daily Bulletin No. 12226), it was widely used in the past, including in our study area (northern Spain). In other areas of the world with less restrictive policies and environmental vigilance, its use can largely exceed the legal thresholds (e.g., in Panama; Cornejo et al., 2019).

\subsection{Leaf litter}

We used litter from 3 broadleaf senescent trees, which represent common litter inputs to headwater streams in our study area and display a gradient of litter quality (i.e., nutrient concentrations and toughness): (1) black alder, Alnus glutinosa (L.) Gaertn., a dominant riparian species with high-quality litter, and widely used in previous relevant studies; (2) chestnut, Castanea sativa Mill., a common species in Atlantic mixed forests with litter of medium quality; and (3) oak, Quercus robur L., also typical of Atlantic mixed forests but with low-quality litter. We collected recently fallen leaves of these species from the forest floor in the Agüera stream catchment in northern Spain $\left(43.21^{\circ} \mathrm{N}, 3.27^{\circ} \mathrm{W}\right)$ in October 2017, and then air-dried and stored them in the laboratory.

\subsection{Aquatic hyphomycetes}

In order to obtain a representative $\mathrm{AH}$ assemblage, we collected mixed litter in different stages of decomposition (total dry mass, DM = $18.5 \mathrm{~g}$ ) from natural leaf packs in the benthos of Perea stream, a tributary of the Agüera stream $\left(43.291^{\circ} \mathrm{N}, 3.243^{\circ} \mathrm{W}\right)$, in November 2018. The mixture contained A. glutinosa (28\%), C. sativa (28\%), Corylus avellana L. (16\%), Q. robur (14\%), Platanus $\times$ hispanica Mill. ex Münch. (9\%) and Salix atrocinerea Brot. (5\%). This litter was incubated at $10{ }^{\circ} \mathrm{C}$ in a glass jar with $2.2 \mathrm{~L}$ of filtered $(100 \mu \mathrm{m})$ stream water with aeration for $6 \mathrm{~d}$, with water renewed every $24 \mathrm{~h}$. This water was used as microbial inoculum ( $10 \mathrm{~mL}$ per microcosm $)$ at the beginning of the experiment (day 0).

Additionally, eight 10-mL samples were stored in 45-mL centrifuge tubes in order to characterize the initial AH conidial assemblage. Samples were pre-stained with 2 drops of $0.05 \%$ trypan blue in $60 \%$ lactic acid, preserved with $2 \mathrm{~mL}$ of $35 \%$ formalin and adjusted to $35 \mathrm{~mL}$ with 
distilled water. We then added $150 \mu \mathrm{L}$ of Triton X-100 (0.5\%) to each sample and mixed it with a magnetic stirrer to ensure a uniform distribution of conidia. A sub-sample of $10-15 \mathrm{~mL}$ was filtered $(25 \mathrm{~mm}$ diameter, pore size $5 \mu \mathrm{m}$, Millipore SMWP, Millipore Corporation) with gentle vacuum (Descals, 2005). Filters were stained and conidia were identified and counted under a microscope at $200 \times$ magnification (Gulis et al., 2005). The initial AH conidial assemblage was composed of 11 taxa (see Suppl. Material: SM Table S1, Inoc.), Flagellospora curvula Ingold being the most abundant species followed by Lunulospora curvula Ingold, Alatospora acuminata Ingold and Articulospora tetracladia Ingold. We estimated that ca. 300 conidia were added to each microcosm.

\subsection{Invertebrates}

We used larvae of the cased caddisfly Sericostoma pyrenaicum Pictet (Trichoptera: Sericostomatidae), which is a common detritivore in the study area, previously used in experiments assessing litter decomposition (Correa-Araneda et al., 2017; Tonin et al., 2017; López-Rojo et al., 2018, 2019). Larvae of similar size (mean case length \pm SE: $12.78 \pm$ $0.16 \mathrm{~mm}$; larval instar between IV and VII based on Basaguren et al., 2002) were collected manually from the benthos of Perea stream in November 2018 and transported to the laboratory in refrigerated containers. They were acclimated within a controlled-temperature room set at $10^{\circ} \mathrm{C}$ for 4 days (fed ad libitum with mixed litter), and starved for $48 \mathrm{~h}$ just before the beginning of the experiment. Initial invertebrate DM (mg) was estimated from a case length (CL, mm)/DM relationship calculated using 30 extra larvae (DM $=0.1267 \mathrm{e}^{0.2879 \times C L}, \mathrm{r}^{2}=0.91$; SM Fig. S1), which followed an allometric relationship as in previous studies (López-Rojo et al., 2018).

\subsection{Experimental procedure and sample processing}

Microcosms consisted of 580-mL glass jars containing $300 \mathrm{~mL}$ of filtered $(100 \mu \mathrm{m})$ water from the Perea stream [mean soluble reactive phosphorus (SRP) $\pm \mathrm{SE}=11.66 \pm 2.06 \mu \mathrm{g} \mathrm{L}^{-1}$; mean dissolved inorganic nitrogen (DIN) $\left.\pm \mathrm{SE}=560.34 \pm 17.74 \mu \mathrm{g} \mathrm{L}^{-1}\right]$ plus $10 \mathrm{~mL}$ of the microbial inoculum, and $0.9075 \pm 0.0017 \mathrm{~g}$ (mean $\pm \mathrm{SE}$ ) of air-dried litter of A. glutinosa (Ag), C. sativa (Cs), Q. robur (Qr) or the 3-species mixture $(0.3076 \pm 0.0016 \mathrm{~g}$ each; mean $\pm \mathrm{SE})$. Litter fragments were attached with a safety pin in order to prevent them from floating, and to be able to identify fragments from different species in mixtures at the end of the experiment. Microcosms were constantly aerated through pipette tips connected to a pump, and kept within a controlled-temperature room at $10{ }^{\circ} \mathrm{C}$ with a light:dark regime of $12: 12 \mathrm{~h}$.

The 192 microcosms were homogeneously distributed among the different levels of the following factors, with 4 replicates for each combination of factors/levels (SM Fig. S2):

(i) The 'litter pre-treatment' factor had 2 levels: (1) control (no fungicide), and (2) litter pre-treatment. Leaves were pre-treated by spraying them with $3 \mathrm{~mL}$ of chlorothalonil in the application dose concentration $\left(1250 \mu \mathrm{g} \mathrm{L}^{-1}\right) 72 \mathrm{~h}$ prior to their addition to microcosms. The pre-treatment represented the scenario where riparian trees within a catchment subject to agriculture or forestry are accidentally treated with the fungicide.

(ii) The 'waterborne fungicide' factor had 3 levels corresponding to different fungicide concentrations, which represented different scenarios of fungicide inputs through runoff from the catchment: (1) control (no fungicide), (2) low concentration $\left(0.125 \mu \mathrm{g} \mathrm{L}^{-1}\right)$, and (3) high concentration $\left(1.25 \mu \mathrm{g} \mathrm{L}^{-1}\right)$. The low concentration was a 1:10000 dilution of the fungicide application dose, which is between the mean $\left(<0.07 \mu \mathrm{g} \mathrm{L}^{-1}\right)$ and the maximum concentration $\left(0.5 \mu \mathrm{g} \mathrm{L}^{-1}\right)$ found in U.S. fresh waters (Elias and Bernot, 2014). The high concentration was a 1:1000 dilution of the application dose, which is above the maximum concentration found in fresh waters but well below peak concentrations found in golf turf outflow (48.1 $\mathrm{g} \mathrm{L}^{-1}$ ) (King and Balogh, 2013).

(iii) The 'litter type' factor had 4 levels: litter of Ag, Cs, Qr, and the 3species mixture.

(iv) The 'invertebrate presence' factor had 2 levels: presence (2 larvae of $S$. pyrenaicum per microcosm) and absence (no larvae), which allowed quantifying total and microbial decomposition, respectively.

Before the experiment started, litter in each microcosm was immersed in filtered stream water for $48 \mathrm{~h}$, with water replacement at $24 \mathrm{~h}$, in order to promote the leaching of soluble compounds (Bärlocher, 2005) and, in pre-treated litter, the release of any excess fungicide not adhered to the leaves. Afterwards, water was replaced with new filtered stream water, which included the corresponding waterborne fungicide plus the microbial inoculum. Half of the microcosms received 2 invertebrates (mean $\mathrm{DM} \pm \mathrm{SE}=12.21 \pm 0.58 \mathrm{mg}$ ), while the other half remained without invertebrates. The experiment was run for $28 \mathrm{~d}$, with water replacement of each waterborne fungicide concentration (control, low and high) on days 7, 14, 21 and 26. Invertebrate survival was checked at every water replacement. On day 28 , litter fragments were separated by species, oven-dried $\left(70^{\circ} \mathrm{C}, 48 \mathrm{~h}\right)$ and weighed to calculate their DM, and then incinerated $\left(500^{\circ} \mathrm{C}, 4 \mathrm{~h}\right)$ and re-weighed to calculate ash-free dry mass (AFDM).

Water in microcosms without invertebrates was renewed on day 26, and filtered on day 28 to assess sporulation rate and fungal assemblage composition during the last 2 days. From each of these microcosms ( $\mathrm{n}=$ 96) we took a $25-\mathrm{mL}$ aliquot, which was examined as described above for the characterization of the initial $\mathrm{AH}$ assemblage. Sporulation rate was expressed as the number of conidia per mg of litter (AFDM) and day. Invertebrates were kept for $48 \mathrm{~h}$ (from day 28 to day 30 ) in microcosms with new, filtered stream water, but no litter, so they had no food in their guts as at the beginning of the experiment. They were then freeze-dried, and their final DM, nitrogen $(\mathrm{N})$ concentration (\% DM; PerkinElmer series II CHNS/O elemental analyzer) and phosphorus (P) concentration (\% DM; spectrometer after autoclave-assisted extraction; APHA, 1998) were determined (as in López-Rojo et al., 2019).

We used 24 extra microcosms to quantify the initial leaching of soluble compounds. Each microcosm contained $0.30 \mathrm{~g}$ of $\mathrm{Ag}$, Cs or Qr litter ( 8 microcosms per species), half of them pre-treated with chlorothalonil in the same concentrations and proportion as for experimental litter $\left(1 \mathrm{~mL} ; 1250 \mu \mathrm{g} \mathrm{L}^{-1}\right)$. After $48 \mathrm{~h}$, half of the litter was used to estimate initial, post-leaching AFDM (as above), and the other half was used to measure $\mathrm{N}$ and $\mathrm{P}$ concentrations (as above) and specific leaf area [SLA; area $\left(\mathrm{mm}^{2}\right)$ divided by DM (mg) measured in five $12-\mathrm{mm} \varnothing$ leaf discs per sample], which together represented litter quality.

\subsection{Data analysis}

Proportional litter mass loss [LML = (final AFDM - initial AFDM)/ initial AFDM] was used to quantify leaching losses (in extra microcosms), microbial decomposition (in experimental microcosms without invertebrates), and total decomposition (in experimental microcosms with invertebrates). Initial AFDM was estimated based on the extra microcosms used to quantify leaching losses.

We analysed the effect of litter pre-treatment on leaching (LML) and post-leaching $\mathrm{N}$ and $\mathrm{P}$ concentrations and SLA (hypothesis 1) by examining overlap of bootstrapped 95\% confidence intervals ("boot.ci" function in the boot package of R statistical software; R Core Team, 2019) for untreated and pre-treated litter of each species (Ag, Cs and Qr), to test the null expectation that there is no effect of litter pre-treatment.

We examined and compared litter pre-treatment and waterborne fungicide effects on invertebrate survival (partially addressing hypotheses 2-6) with the Kaplan-Meier product-limit method ("surv" function in the survival $\mathrm{R}$ package, which measures the rate at which death occurs 
as median time to death (Bland and Altman, 1998). We explored differences among treatments for each litter type (Ag, Cs, Qr and mixture) with the "cox.ph" function in the survival R package (Ferreira et al., 2010; Martins et al., 2016). Invertebrate growth was calculated in terms of proportional change in detritivore DM and $\mathrm{N}$ and $\mathrm{P}$ content [(final value - initial value)/initial value]; however, because of high mortality, we could not examine differences in these variables among treatments.

We examined the effects of litter pre-treatment (hypothesis 2), waterborne fungicide (hypothesis 3) and their combined effects (hypothesis 4) on AH sporulation rate and taxon richness and LML (with and without invertebrates), and whether such effects varied among litter types (hypothesis 5), using linear models (" $\mathrm{lm}$ " function in the nlme $\mathrm{R}$ package; Pinheiro et al., 2009). Litter pre-treatment (treated and untreated), waterborne fungicide concentration (control, low and high) and species (Ag, Cs and Qr) were all fixed factors in the models. Additionally, we examined whether fungicide effects differed between monocultures and the mixture (hypothesis 6) with linear mixed models ("Ime" function, nlme R package; Pinheiro et al., 2009). Litter pre-treatment, waterborne fungicide and litter diversity ( 1 and 3 species) were fixed factors, and litter type (Ag, Cs and Qr) was a random factor. In both cases, we ran separate analyses for microcosms with and without invertebrates, to avoid very complex models with too many interactions (Tonin et al., 2017, 2018).

We examined variation in $\mathrm{AH}$ assemblage structure for each litter type with non-metric dimensional scaling (NMDS) based on the Bray Curtis similarity index of conidial abundance data, using the "metaMDS" function of the vegan R package. Differences in AH assemblages between litter pre-treatments and waterborne fungicide concentrations (partially addressing hypotheses 2-5) were calculated with permutational multivariate analysis of variance ("adonis" function of the vegan $\mathrm{R}$ package), and the contribution of each $\mathrm{AH}$ species to each treatment was examined with the similarity percentage procedure SIMPER ("simper" function of the vegan $\mathrm{R}$ package).

To further test hypothesis 4 (additive effects of both exposure modes), hypothesis 5 (different strength of fungicide effects among litter types) and hypothesis 6 (the litter mixture mitigating fungicide effects), we assessed the effect sizes of each treatment on each variable. We first calculated the log ratio between the value for each fungicide treatment and the control. We then calculated the distance between the effect size of the observed value in combined treatments (i.e., pre-treated litter with low or high waterborne fungicide) and the expected one (calculated as the sum of the effect size of pre-treated litter and waterborne fungicide separately; Jackson et al., 2016). We finally calculated bootstrapped 95\% confidence intervals ("boot.ci" function in the boot $\mathrm{R}$ package) of these distances for each litter type (Ag, Cs, Qr and the mixture) to see whether these intervals contained the value of 0 (i. e. the null expectation that the observed value did not differ from the expected one, meaning that the combined effect is additive); alternatively, the
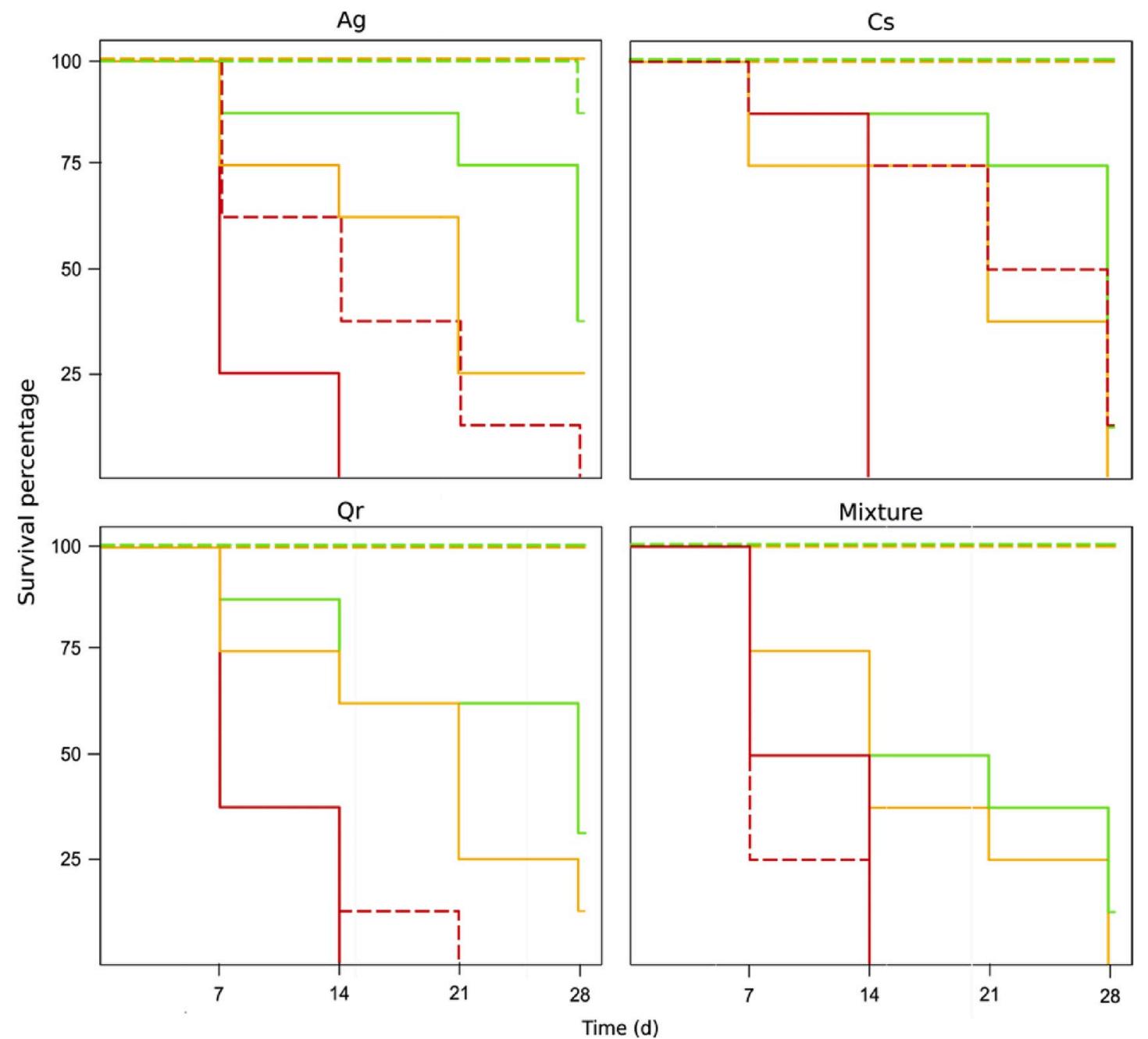

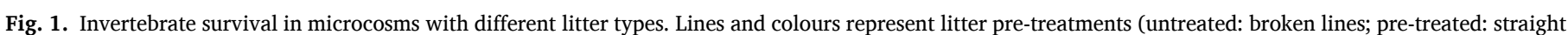

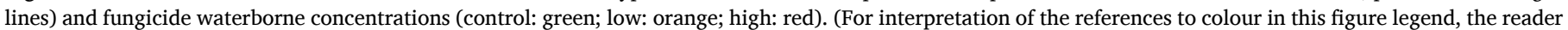
is referred to the Web version of this article.) 
observed effect could be higher than the expected one (i.e., synergistic effect, represented by negative values) or lower (i.e., antagonistic effect, represented by positive values).

\section{Results}

Litter pre-treatment had no effect on LML, N and P content or SLA during the leaching period (SM Fig. S3). In the decomposition experiment, all the assessed variables (invertebrate survival, AH sporulation rate, taxon richness and assemblage structure, and microbial and total litter decomposition) were negatively affected by litter pre-treatment and by waterborne fungicide concentration (Figs. 1-4). Unexpectedly, there was high mortality of invertebrates in all treatments, except for those with control or low waterborne fungicide concentration combined with untreated litter (Fig. 1). The lowest survival occurred in the high waterborne concentration combined with pre-treated litter (median time to death, TTD: 10.5 days). There were no significant differences among litter types in the effect of litter pre-treatment or waterborne fungicide on survival (Fig. 1). However, when comparing TTD ranges of each litter type we found some differences: invertebrates fed Cs leaves presented the lowest mortality (TTD: 14-28 days), while those fed the mixture showed the highest mortality (TTD: 7-14 days, SM Table S1).

Sporulation rate was strongly reduced in response to fungicide exposure (pre-treatment, $\mathrm{p}<0.001$; waterborne, $\mathrm{p}<0.001$; SM Tables S3 and S4); in 8 samples with waterborne fungicide (6 of which also had pre-treated litter) we found no conidia. A total of $18 \mathrm{AH}$ sporulating taxa were found at the end of the decomposition experiment (SM Table S2). Control samples contained most of these taxa (15), while microcosms exposed to the fungicide (litter pre-treatment or waterborne) showed a notable reduction in $\mathrm{AH}$ sporulation rate and taxon richness (Fig. 2). However, the overall negative fungicide effects on sporulation rate and taxon richness (SM Tables S3 and S4) varied in magnitude (i.e., effect size) depending on litter type (SM Fig. S4). In the case of sporulation rate there was an interaction between litter type and fungicide waterborne concentration ( $p<0.001$; SM Table S3) and between litter diversity and both fungicide exposure modes (SM Table S4). The combined effect of both exposure modes on sporulation rate were in general antagonistic for all litter types (i.e., the observed effect was lower than the expected one), independently of waterborne concentration; only Qr litter under low waterborne fungicide concentration showed additive effects. The litter mixture presented the most marked antagonistic effects on AH sporulation (SM Fig. S5), but it also had the greatest single effect of each exposure mode, so it is not surprising that combined effects were lower than the sum of single effects (Fig. 2 and SM Fig. S4).

The reduction in taxon richness was more constant across litter types or diversity levels (SM Tables S2 and S3). When the two exposure modes were combined, taxon richness generally showed additive effects under low waterborne fungicide concentration, and antagonistic effects under high concentration. The exception were microcosms with Ag litter, with synergistic effects at the high concentration of waterborne fungicide (i. e., the observed value was higher than the expected one; SM Fig. S5). In general, fungicide effects on AH performance, rather than being lessened by litter diversity, were mostly maintained or increased in litter mixtures compared to monocultures (SM Fig. S4).

$\mathrm{AH}$ assemblage structure was influenced by waterborne fungicide for all litter types, but the effect of litter pre-treatment varied across litter types (Fig. 3 and SM Table S5). The structure of conidial assemblages from microcosms with Qr litter was not affected by litter pre-treatment. The species with the highest contribution to dissimilarities among groups due to litter pre-treatments or waterborne concentrations were mainly dominant species such as Articulospora tetracladia Ingold and Flagellospora curvula Ingold, which in the presence of the fungicide greatly reduced their sporulation capacity (SM Table S2). In Qr litter, another three species became relevant: Anguillospora filiformis Greath., also an abundant species whose contribution severely decreased in

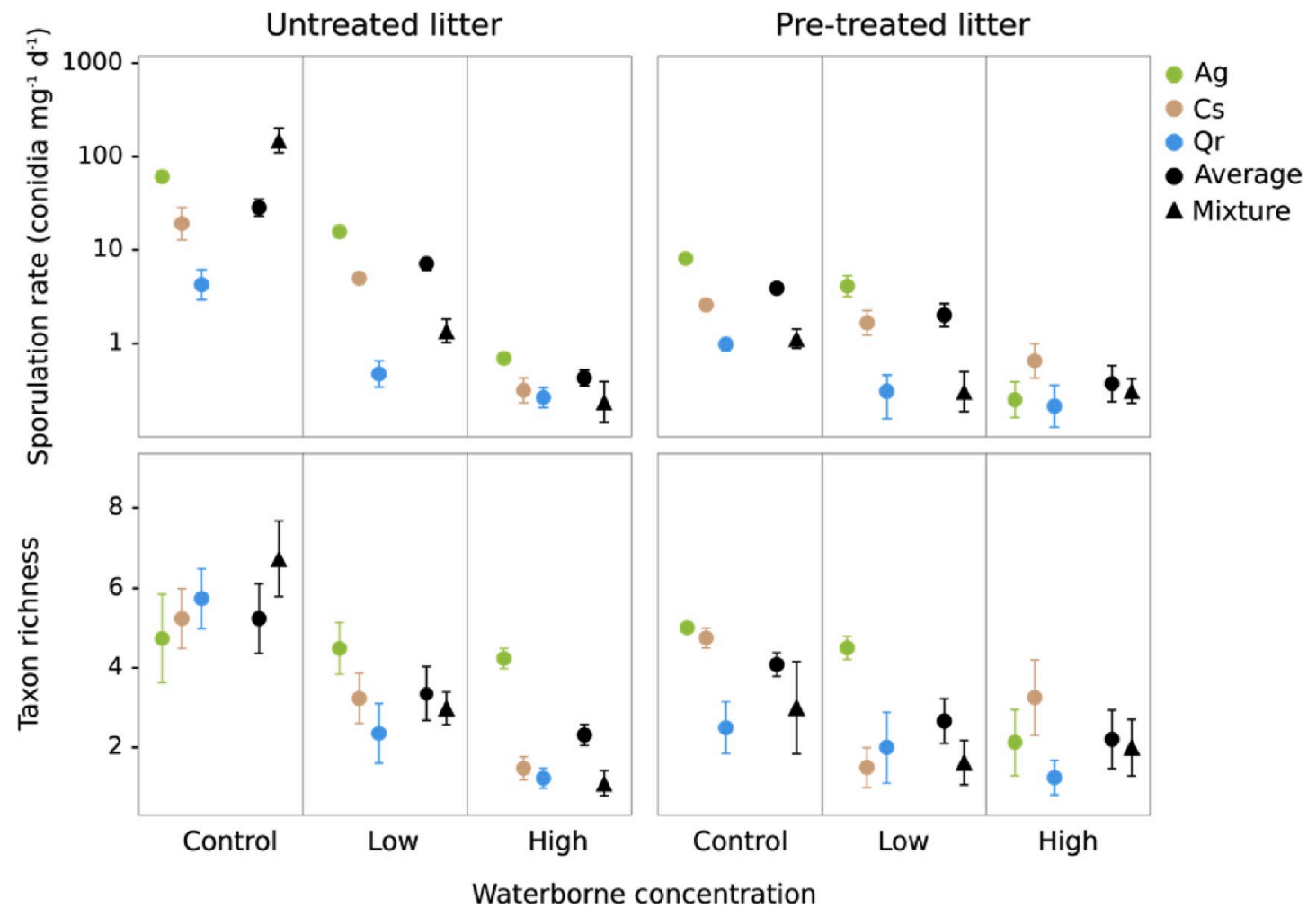

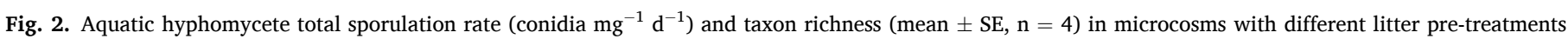

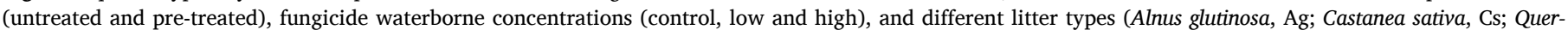
cus robur, Qr), the average of the three monocultures, and the mixture. 


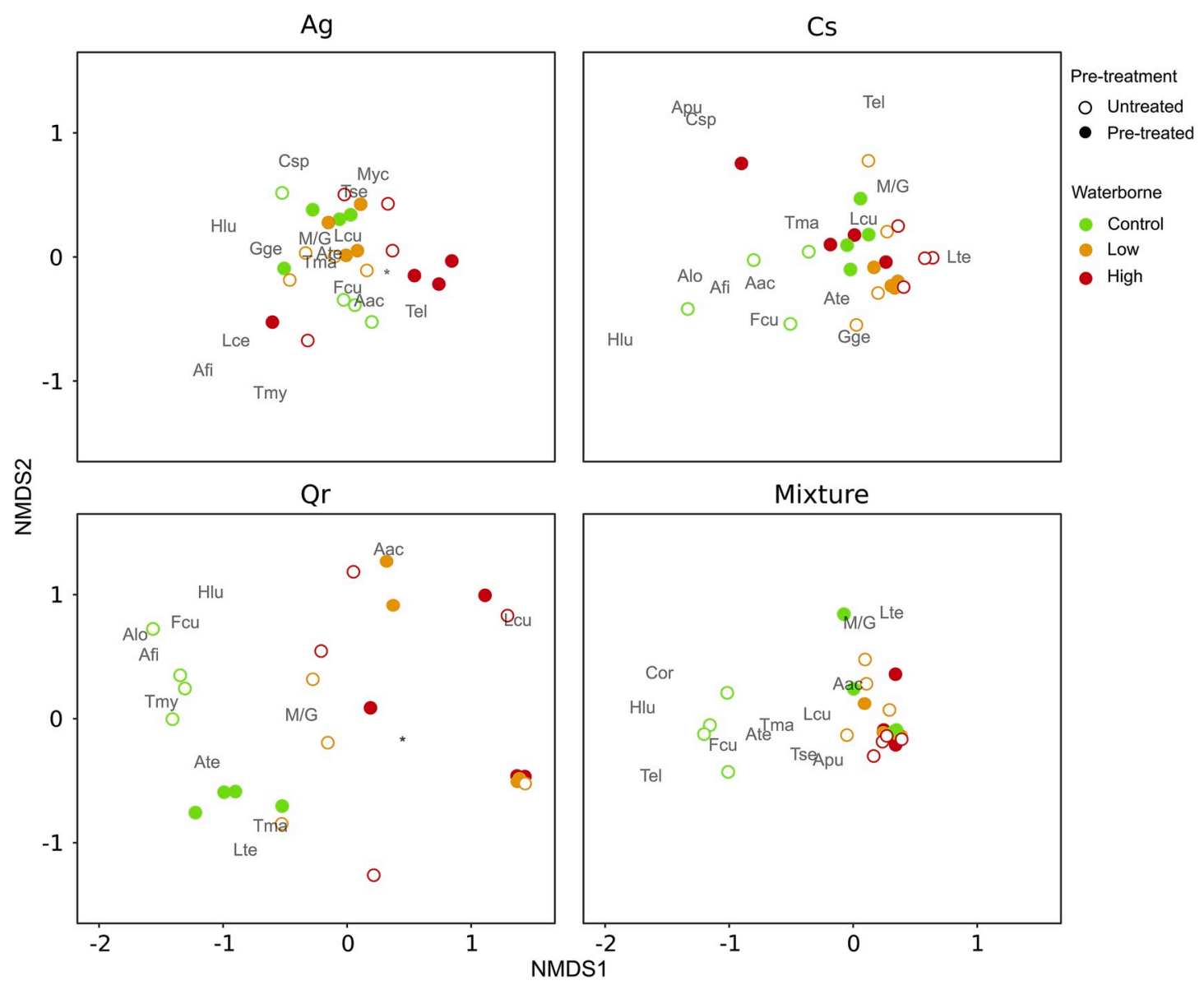

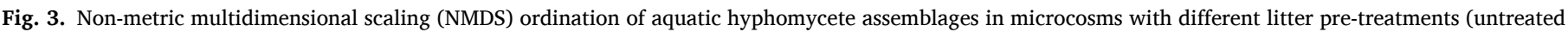

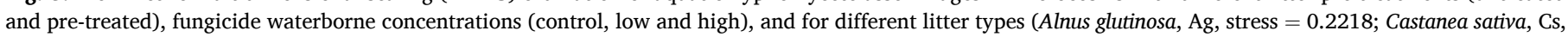
stress $=0.1481$; Quercus robur, Qr, stress $=0.1523$ ) and the mixture (stress $=0.098$ ). Aquatic hyphomycete species: see SM Table S2.

presence of the fungicide, and Lunulospora curvula Ingold and Tetracladium marchalianum De Wild., which increased their relative contribution in presence of the fungicide.

Decomposition was affected by litter pre-treatment and waterborne fungicide concentration in microcosms with and without invertebrates (Fig. 4 and SM Tables S3 and S4). In microcosms with invertebrates, these effects were generally negative (SM Fig. S4), but were not significant in untreated monocultures under low waterborne fungicide concentration. Microcosms without invertebrates showed more variable responses to fungicide exposure (Fig. 4). Some of these effects, especially those associated with pre-treatment, were litter-type dependent ( $\mathrm{p}<$ 0.001; SM Table S3). In treatments with untreated leaves, Ag and Qr showed higher LML at low concentration (and at high concentration for $\mathrm{Ag}$ ) than in control water (Fig. 4). Comparison of the observed effects of both fungicide exposure modes applied simultaneously with their expected effects on decomposition (SM Fig. S5), provided examples of additive, synergistic and antagonistic effects, which were variable even within a given litter type, depending on concentration in the water and the presence of invertebrates. Additive effects were observed for Ag and Cs decomposition in the presence of invertebrates at high waterborne concentration, and for Cs microbial decomposition at low waterborne concentration. Antagonistic effects were predominant in the other combinations, except for Ag litter decomposition, which showed synergistic effects. The observed negative effects of both exposure modes were never reduced in the presence of the litter mixture compared to monocultures (SM Fig. S4). Furthermore, litter diversity did not interact with any fungicide effects on decomposition (SM Table S4).

\section{Discussion}

Studies exploring the effects of fungicides on stream ecosystems and their animal communities are increasingly common, and have provided valuable knowledge about their functioning and integrity (Zubrod et al., 2015a). However, there are still key research gaps (Beketov and Liess, 2012), some of which we have addressed in this study, namely, the combined effects of different fungicide exposure modes on litter decomposition, microbial decomposers and a common detritivorous invertebrate, and the variation in fungicide effects resulting from differences in litter quality and species identity. Our results demonstrate that both high and low fungicide concentrations cause invertebrate mortality, reduce sporulation rates and taxon richness of fungal assemblages, and slow down total and microbial litter decomposition. Most of these effects differed among litters types, and were not mitigated by litter diversity.

\subsection{Litter pre-treatment with the fungicide produced minimal effects on litter traits}

We found that the pre-treatment barely modified litter traits. This contrasts with the alteration of physicochemical properties of litter resulting from its exposure to other stressors, such as extreme temperatures (Pérez, pers. comm.; Correa-Araneda et al., 2020). The lack of effect could be related to the fact that chlorothalonil, and more specifically DACONIL 50SC, is a broad spectrum, non-systemic pesticide, formulated to be directly applied on the leaf surface of living terrestrial plants, and it has been shown to have no negative effects on them (EPA, 


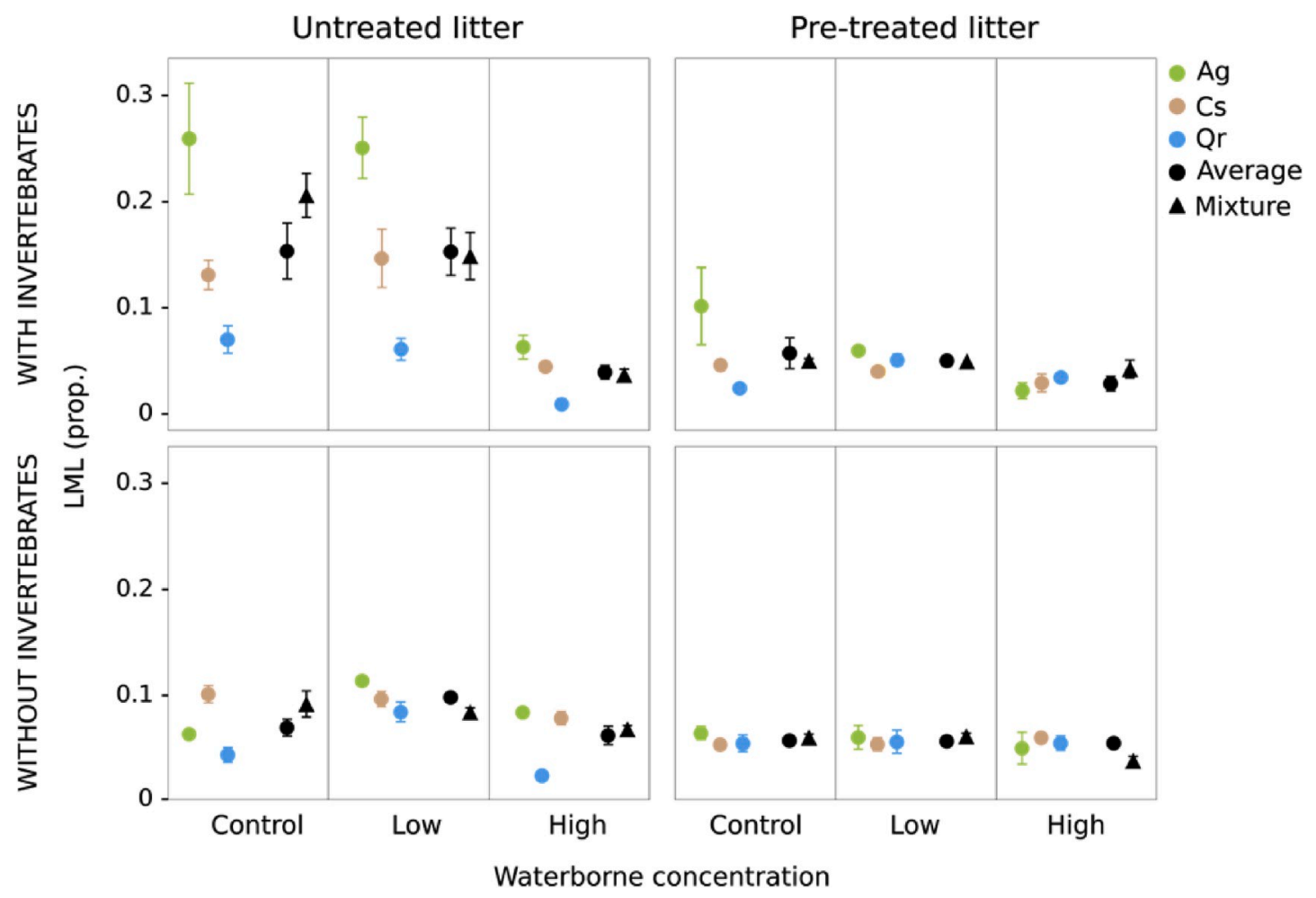

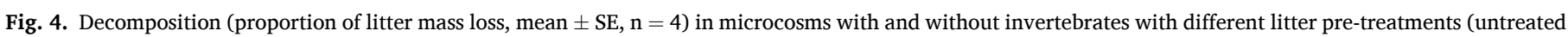

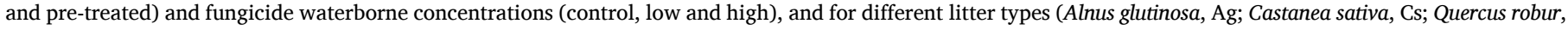
Qr), the average of the three monocultures, and the mixture.

1999).

\subsection{Fungicide exposure leads to lethal effects on invertebrates}

Our experiment showed that the fungicide impaired the survival of the common detritivorous insect Sericostoma pyrenaicum, matching previous results with detritivorous crustaceans such as Echinogammarus berilloni (Flores et al., 2014a) and Gammarus fossarum (Zubrod et al., 2014, 2017). This is noteworthy because we used waterborne concentrations $\left(0.125\right.$ and $\left.1.25 \mu \mathrm{g} \mathrm{L}^{-1}\right)$ that were environmentally relevant and well below non-effect concentrations observed in chronic toxicity tests with microcrustacean daphnids (NOEC: $9 \mu \mathrm{g} \mathrm{L}^{-1}$ ) (Elias and Bernot, 2014). Our results suggest that extrapolating results from ecotoxicological assays with daphnids (where most information comes from; EPA, 1999) to other taxa may underestimate the real effects of fungicides for communities and ecosystems. Different taxa are likely to have different degrees of tolerance to fungicides (Feckler et al., 2012; Vigneron et al., 2019), and differences are likely to be high between crustaceans and insects, which differ in structure and physiology (Tachet et al., 2000). Thus, future ecotoxicological studies should aim to reflect natural communities as much as possible (Beketov and Liess, 2012), including assessments of long-term effects and multispecies toxicity bioassays (Steyna et al., 2019).

The use of different fungicides and different exposure modes can also explain differences among experiments (Maltby et al., 2009). For example, we found the greatest invertebrate mortality in the litter pre-treatment with fungicide, while others have found no mortality in G. fossarum fed litter that had been conditioned in water with a fungicide (Rossi et al., 2018), or litter from trees which had been treated with systemic fungicides for 6 weeks (Newton et al., 2018). In these cases, fungicide treatments were more indirect than in our experiment, in which the fungicide was sprayed on the litter 2 days before the beginning of the experiment and/or added to the water in experimental microcosms. Our waterborne concentrations resulted from direct dilutions
(1:1000 and 1:10000) of the fungicide application dose, although we did not monitor concentrations during the experiment, and it is possible that the litter pre-treatment increased the fungicide concentration in the water.

Unexpectedly, we found that litter diversity had no influence on invertebrate survival, which nevertheless varied with litter type: individuals fed Cs survived more than those fed other litter types. This could be related to the low stoichiometric quality of Cs litter, which could enhance survival of invertebrates exposed to toxic substances. For example, mortality of $G$. fossarum exposed to cadmium was greater when the animals were fed higher quality litter, possibly because of increased moulting and metabolism, which would have led to higher sensitivity and toxic uptake rate (Arce-Funck et al., 2018). In our experiment, however, Qr litter (also of low quality) caused similar mortality to that of $\mathrm{Ag}$ litter (of high quality). Therefore, more studies are needed to understand the interaction between litter quality and consumer sensitivity to fungicides. The high mortality rates in our experiment obscured possible sublethal effects that might modify consumption and, therefore, litter mass loss (Flores et al., 2014a, 2014b). For example, previous studies with $G$. fossarum found sublethal reduction in invertebrate growth due to fungicides (Zubrod et al., 2015b, 2017).

\subsection{Severe fungicide effects on the AH assemblage}

AH assemblages are known to suffer reductions in biomass, sporulation rate and taxon richness due to fungicides (Zubrod et al., 2011, 2015a, 2015b, 2017; Dimitrov et al., 2014; Flores et al., 2014a). Our study supported these findings, as both exposure modes caused a large decrease in sporulation rate and taxon richness. Only under control conditions did the number of sporulating taxa increase after the incubation, as usually observed (e.g., Pérez et al., 2012). Furthermore, contrary to what we observed for invertebrates, we found a large shift in $\mathrm{AH}$ sporulation and taxon richness at the low waterborne concentration. This was expected because fungi are the primary target of fungicides, 
and it matches the findings of previous studies (Flores et al., 2014a; Zubrod et al., 2015b).

Under control conditions, litter diversity tended to increase sporulation rate and taxon richness but, contrary to our expectation (Duarte et al., 2008), it had the opposite effect in the presence of the fungicide. In terms of the $\mathrm{AH}$ assemblage structure, the fungicide caused a large reduction mostly in sporulation of predominant species (Articulospora tetracladia and Flagellospora curvula), as observed elsewhere (Sridhar et al., 2001; Duarte et al., 2008). These are typically the two most abundant species found in litter decomposition studies carried out in our study area (Pérez et al., 2012, 2018). In the case of Qr, another common species, Anguillospora filiformis, also suffered a reduction in abundance in both fungicide treatments. This species is considered sensitive to pollution in some studies (Duarte et al., 2008), whereas in others it has been reported as resistant (Sridhar et al., 2001); this variability may be due to different resistance of $A$. filiformis to different pollutants. For other key accompanying species, such as Tetracladium marchalianum and Lunulospora curvula, the fungicide exposure caused no change in sporulation rate but resulted in an increase of their relative abundance, as other common species declined. Tetracladium marchalianum has been described as a fungicide-resistant species (Zubrod et al., 2015a, 2015b), but the observed resistance of $L$. curvula contrasts with other studies, where it suffered a reduction due to fungicides (Flores et al., 2014a) or other pollutants (Duarte et al., 2008). These contradictory results highlight the necessity for more studies assessing the tolerance of AHs to chemical stressors.

\subsection{The fungicide reduces litter decomposition}

Under control conditions, the observed decomposition rate in the presence of invertebrates was comparable to previous studies, ranging from 0.19 to $0.58 \mathrm{mg}$ per $\mathrm{mg}$ of invertebrate per day (Qr and $\mathrm{Ag}$, respectively). In a microcosm experiment with $S$. pyrenaicum, Lopéz-Rojo et al. (2018) found decomposition rates from 0.11 to $0.17 \mathrm{mg}$ per $\mathrm{mg}$ of invertebrate per day for $\mathrm{Qr}$ and from 0.42 to 0.57 for Ag. The rate at which $S$. pyrenaicum fed on $\mathrm{Ag}$ in our study was also comparable to that of $G$. fossarum, usually between 0.3 and $0.6 \mathrm{mg}$ per $\mathrm{mg}$ of invertebrate and day (Zubrod et al., 2014). These similarities among experiments, despite their methodological differences, indicate their comparability.

In our experiment, decomposition mediated by $S$. pyrenaicum was significantly reduced by exposure to chlorothalonil, in agreement with studies with Gammarus spp. (Dimitrov et al., 2014; Zubrod et al., 2014, 2017) and the caddisfly Chaetopteryx villosa Fabricius (Konschak et al., 2019) exposed to other fungicides, but contrasting with experiments finding no effects (Zubrod et al., 2011). The wide variety of fungicides and invertebrates used in experiments precludes any generalization currently. For example, our litter pre-treatment aimed to simulate the fungicide application mode (i.e., spraying fungicide on leaves), while other studies pre-treated litter by exposing it to fungicides in the water column during their initial conditioning, resulting in smaller effects than those observed here (Zubrod et al., 2011, 2015b, 2017; Flores et al., 2014a; Rossi et al., 2018).

There are no previous studies on the effect of chlorothalonil on microbial decomposition, with only one relevant study to our knowledge, focused on nutrient uptake rate of benthic microorganisms (Elias and Bernot, 2014). We found a decrease of microbial decomposition in pre-treated litter, but the waterborne fungicide effects were more complex: decomposition was higher at the low concentration, suggesting a subsidy effect of the fungicide (sensu Odum et al., 1979), as previously observed for other toxic compounds (Swift et al., 1988), or a shift in the relative contribution of fungi and bacteria to microbial decomposition (Gulis and Suberkropp, 2003). Previous studies have shown a variety of responses of microbial decomposition to fungicides, from severe reductions after waterborne exposition (Zubrod et al., 2015a; Rossi et al., 2018) to non-significant effects with pre-treated litter (Dimitrov et al., 2014) or waterborne fungicides (Zubrod et al., 2015a). Furthermore, Zubrod et al. (2017) failed to find effects on microbial decomposition when combining five different fungicides with different exposure modes. Although the key role of AHs for this ecosystem process is well known (Bärlocher, 1985; Pérez et al., 2012), ecotoxicological knowledge regarding this group of microorganisms is still scarce (Maltby et al., 2009; Zubrod et al., 2011).

\subsection{Aquatic environmental management should consider effects of terrestrially derived pesticides}

This study used different waterborne fungicide concentrations and pre-treated litter in order to mimic different inputs of fungicides that occur in stream ecosystems. We provided evidence of harmful effects of fungicides on invertebrate survival, AH assemblages and litter decomposition, as a result of both exposure modes. Our findings, together with those of other studies cited here, which have assessed a variety of fungicides and organisms, demonstrate the strong potential of terrestrially derived fungicides for altering stream assemblages and ecosystem functioning. These results highlight the necessity for more ecotoxicological tests on invertebrates, particularly those that are key components of stream food webs and ecosystem processes (Beketov and Liess, 2012), and on aquatic hyphomycetes, which are also key contributors to ecosystem processes and highly sensitive to fungicides, but whose responses are mostly unknown (Maltby et al., 2009; Zubrod et al., 2011). Lastly, our results suggest that fungicide exposure is not necessarily mitigated by litter diversity. Consequently, even streams surrounded by diverse riparian vegetation may suffer damage from fungicide exposure, regardless of its origin. As a whole, our results highlight the importance of protecting stream ecosystems from fungicide pollution, not only from runoff but also from pre-treated litter inputs, regardless of the condition of the riparian forest.

\section{Declaration of competing interest}

The authors declare that they have no known competing financial interests or personal relationships that could have appeared to influence the work reported in this paper.

\section{CRediT authorship contribution statement}

Aydeé Cornejo: Conceptualization, Funding acquisition, Investigation, Writing - original draft, Writing - review \& editing. Javier Pérez: Conceptualization, Investigation, Methodology, Data curation, Validation, Visualization, Writing - original draft, Writing - review \& editing. Alberto Alonso: Investigation, Formal analysis, Writing - original draft, Writing - review \& editing. Naiara López-Rojo: Investigation, Formal analysis, Visualization, Writing - review \& editing. Silvia Monroy: Investigation, Methodology, Data curation, Writing - review \& editing. Luz Boyero: Conceptualization, Funding acquisition, Methodology, Supervision, Writing - review \& editing.

\section{Acknowledgements}

We thank Richard Pearson and two anonymous reviewers for their comments on the manuscript. This study was derived from AC's $\mathrm{PhD}$ thesis and AA's MSc thesis. AC was supported by a fellowship of the National Secretariat of Science, Technology and Innovation (SENACYT) and the National Research System of Panama (SNI). SM was supported by a postdoctoral grant from the University of the Basque Country. Additional funding was obtained from the Spanish Ministry for Science, Innovation and Universities and FEDER (project BioLoss, RTI2018095023-B-I00) and Basque Government funds (IT951-16). 
Appendix A. Supplementary data

Supplementary data to this article can be found online at https://doi. org/10.1016/j.jenvman.2020.110425.

\section{References}

Allison, S.D., Martiny, J.B., 2008. Colloquium paper: resistance, resilience, and redundancy in microbial communities. Proc. Natl. Acad. Sci. U. S. A. 105 (Suppl. 1), $11512-11519$.

APHA, 1998. Phosphorus: automated ascorbic acid reduction method, 4500-P, F. In: Franson, M.A.H. (Ed.), Standard Methods for the Examination of Water and Wastewater, twentieth ed. American Public Health Association, Washington, D. C., pp. $148-149$

Arce-Funck, J., Crenier, C., Danger, M., Billoir, E., Usseglio-Polatera, P., Felten, V., 2018. High stoichiometric food quality increases moulting organism vulnerability to pollutant impacts: an experimental test with Gammarus fossarum (Crustacea: Amphipoda). Sci. Total Environ. 645, 1484-1495.

Arroita, M., Aristi, I., Diez, J., Martinez, M., Oyarzun, G., Elosegi, A., 2015. Impact of water abstraction on storage and breakdown of coarse organic matter in mountain streams. Sci. Total Environ. 503-504, 233-240.

Artigas, J., Majerholc, J., Foulquier Margoum, C., Volat, B., Neyra, M., Pesce, S.-., 2012. Effects of the fungicide tebuconazole on microbial capacities for litter breakdown in streams. Aquat. Toxicol. 122-123, 197-205.

Bärlocher, F., 1985. The role of fungi in the nutrition of stream invertebrates. Bot. J. Linn. Soc. 91, 83-94.

Bärlocher, F., 2005. Leaching. In: Graça, M.A.S., Bärlocher, F., Gessner, M.O. (Eds.), Methods to Study Litter Decomposition: a Practical Guide. Springer, Dordrecht.

Basaguren, A., Riaño, P., Pozo, J., 2002. Life history patterns and dietary changes of several cadisfly (Trichoptera) species in a northern Spain stream. Arch. Hydrobiol. 155, 23-41.

Beketov, M.A., Liess, M., 2012. Ecotoxicology and macroecology-time for integration. Environ. Pollut. 162, 247-254.

Berenzen, N., Lentzen-Godding, A., Probst, M., Schulz, H., Schulz, R., Liess, M., 2005. A comparison of predicted and measured levels of runoff-related pesticide concentrations in small lowland streams on a landscape level. Chemosphere 58, 683-691.

Bland, J.M., Altman, D.G., 1998. Survival probabilities (the Kaplan-Meier method. BMJ $317,1572-1580$.

Boyero, L., Pearson, R.G., Dudgeon, D., Graça, M.A.S., Gessner, M.O., Albariño, R.J., Ferreira, V., Yule, C.M., Boulton, A.J., Arunachalam, M., Callisto, M., Chauvet, E., Ramírez, A., Chará, J., Moretti, M.S., Gonçalves, J.F., Helson, J.E., Chará-Serna, A M., Encalada, A.C., Davies, J.N., Lamothe, S., Cornejo, A., Li, A.O.Y., Buria, L.M., Villanueva, V.D., Zúñiga, M.C., Pringle, C.M., 2011. Global distribution of a key trophic guild contrasts with common latitudinal diversity patterns. Ecology 92 , 1839-1848.

Boyero, L., Barmuta, L.A., Ratnarajah, L., Schmidt, K., Pearson, R.G., 2012. Effects of exotic riparian vegetation on leaf breakdown by shredders: a tropical-temperate comparison. Freshw. Sci. 31, 296-303.

Chen, S.K., Edwards, C.A., Subler, S., 2001. Effects of the fungicides benomyl, captan and chlorothalonil on soil microbial activity and nitrogen dynamics in laboratory incubations. Soil Biol. Biochem. 33, 1971-1980.

Cornejo, A., Tonin, A.M., Checa, B., Tuñon, A.R., Pérez, D., Coronado, E., González, S. Ríos, T., Macchi, P., Correa-Araneda, F., Boyero, L., 2019. Effects of multiple stressors associated with agriculture on stream macroinvertebrate communities in a tropical catchment. PloS One 14(8):e0220528.

Correa-Araneda, F., Basaguren, A., Abdala-Diaz, R.T., Tonin, A.M., Boyero, L., 2017. Resource-allocation tradeoffs in caddisflies facing multiple stressors. Ecol Evol 7 , 5103-5110.

Correa-Araneda, F., Tonin, A.M., Pérez, J., Álvarez, K., López-Rojo, N., Díaz, A., Esse, C. Encina-Montoya, F., Figueroa, R., Cornejo, A., Boyero, L., 2020. Extreme climate events can slow down litter breakdown in streams. Aquat. Sci. 82, 25.

Descals, E., 2005. Techniques for handling ingoldian fungi. In: Graça, M.A.S., Bärlocher, F., Gessner, M.O. (Eds.), Methods to Study Litter Decomposition: a Practical Guide. Springer, Dordrecht.

Dimitrov, M.R., Kosol, S., Smidt, H., Buijse, L., Van den Brink, P.J., Van Wijngaarden, R. P., Brock, T.C., Maltby, L., 2014. Assessing effects of the fungicide tebuconazole to heterotrophic microbes in aquatic microcosms. Sci. Total Environ. 490, 1002-1011.

Du Gas, L.M., Ross, P.S., Walker, J., Marlatt, V.L., Kennedy, C.J., 2017. Effects of atrazine and chlorothalonil on the reproductive success, development, and growth of early life stage sockeye salmon (Oncorhynchus nerka). Environ. Toxicol. Chem. 36, 1354-1364.

Duarte, S., Pascoal, C., Cassio, F., 2008. High diversity of fungi may mitigate the impact of pollution on plant litter decomposition in streams. Microb. Ecol. 56, 688-695.

Elias, D., Bernot, M.J., 2014. Effects of atrazine, metolachlor, carbaryl and chlorothalonil on benthic microbes and their nutrient dynamics. PloS One 9, e109190.

EPA, 1999. Reregistration Eligibility Decision (RED). Chlorothalonil., Washington DC, U. S.

Feckler, A., Thielsch, A., Schwenk, K., Schulz, R., Bundschuh, M., 2012. Differences in the sensitivity among cryptic lineages of the Gammarus fossarum complex. Sci. Total Environ. 439, 158-164.

Fernandez, D., Voss, K., Bundschuh, M., Zubrod, J.P., Schafer, R.B., 2015. Effects of fungicides on decomposer communities and litter decomposition in vineyard streams. Sci. Total Environ. 533, 40-48.
Ferreira, V., Gonçalves, A.L., Godbold, D.L., Canhoto, C., 2010. Effect of increased atmospheric $\mathrm{CO} 2$ on the performance of an aquatic detritivore through changes in water temperature and litter quality. Global Change Biol. 16, 3284-3296.

Flores, L., Banjac, Z., Farre, M., Larranaga, A., Mas-Marti, E., Munoz, I., Barcelo, D., Elosegi, A., 2014. Effects of a fungicide (imazalil) and an insecticide (diazinon) on stream fungi and invertebrates associated with litter breakdown. Sci. Total Environ. 476-477, 532-541.

Flores, L., Larrañaga, A., Elosegi, A., 2014. Compensatory feeding of a stream detritivore alleviates the effects of poor food quality when enough food is supplied. Freshw. Sci. 33, 134-141.

Gardeström, J., Ermold, M., Goedkoop, W., McKie, B.G., 2016. Disturbance history influences stressor impacts: effects of a fungicide and nutrients on microbial diversity and litter decomposition. Freshw. Biol. 61, 2171-2184.

Gessner, M.O., Chauvet, E., 2002. A case for using litter breakdown to assess functional stream integrity. Ecol. Appl. 12, 498-510.

Graça, M.A.S., 2001. The role of invertebrates on leaf litter decomposition in streams - a review. Int. Rev. Hydrobiol. 86, 383-393.

Gulis, V., Suberkropp, K., 2003. Effect of inorganic nutrients on relative contributions of fungi and bacteria to carbon flow from submerged decomposing leaf litter. Microb. Ecol. 45, 11-19.

Gulis, V., Marvanová, L., Descals, E., 2005. An illustrated key to the common temperate species of aquatic hyphomycetes. In: Graça, M.A.S., Bärlocher, F., Gessner, M.O. (Eds.), Methods to Stuty Litter Decomposition: A Practcal Guide. Springer, Dordrecht, the Netherlands.

Jackson, M.C., Lowewen, C.J.G., Vinebrooke, R.D., Chimimba, C.T., 2016. Net effects of multiple stressors in freshwater ecosystems: a meta-analysis. Global Change Biol. 22, 180-189.

King, K.W., Balogh, J.C., 2013. Event based analysis of chlorothalonil concentrations following application to managed turf. Environ. Toxicol. Chem. 32, 684-691.

Kominoski, J.S., Hoellein, T.J., Leroy, C.J., Pringle, C.M., Swan, C.M., 2010. Beyond species richness: expanding biodiversity-ecosystem functioning theory in detritusbased streams. River Res. Appl. 26, 67-75.

Konschak, M., Zubrod, J.P., Baudy, P., Englert, D., Herrmann, B., Schulz, R., Bundschuh, M., 2019. Waterborne and diet-related effects of inorganic and organic fungicides on the insect leaf shredder Chaetopteryx villosa (Trichoptera). Aquat. Toxicol. 206, 33-42.

López-Rojo, N., Martínez, A., Pérez, J., Basaguren, A., Pozo, J., Boyero, L., 2018. Leaf traits drive plant diversity effects on litter decomposition and FPOM production in streams. PloS One 13, e0198243.

López-Rojo, N., Pozo, J., Pérez, J., Basaguren, A., Martínez, A., Tonin, A.M., CorreaAraneda, F., Boyero, L., 2019. Plant diversity loss affects stream ecosystem multifunctionality. Ecology, e02847.

Maltby, L., Brock, T.C., van den Brink, P.J., 2009. Fungicide risk assessment for aquatic ecosystems: importance of interspecific variation, toxic mode of action, and exposure regime. Encironmental Sci. Technol. 43, 7556-7563.

Martínez, A., Larrañaga, A., Pérez, J., Descals, E., Pozo, J., 2014. Temperature affects leaf litter decomposition in low-order forest streams: field and microcosm approaches. FEMS Microbiol. Ecol. 87, 257-267.

Martins, R.T., Melo, A.S., Gonçalves, J.F., Campos, C.M., Hamada, N., 2016. Effects of Climate Change on Leaf Breakdown by Microorganisms and the Shredder Phylloicus Elektoros (Trichoptera: Calamoceratidae) (Hydrobiologia).

Mueller, D.S., Jeffers, S.N., Buck, J.W., 2005. Toxicity of fungicides to urediniospores of six rust fungi that occur on ornamental crops. Plant Dis. 89, 255-261.

Newton, K., Zubrod, J.P., Englert, D., Lüdervald, S., Schell, T., Baudy, P., Konschak, M., Feckler, A., Schulz, R., Bundschuc, M., 2018. The evil within? Systemic fungicide application in trees enhances litter quality for an aquatic decomposer-detritivore system. Environ. Pollut. 241, 549-556.

Odum, E.P., Finn, J.T., Franz, E.H., 1979. Perturbation theory and the subsity-stress gradient. Bioscience 29, 349-352.

Pérez, J., Descals, E., Pozo, J., 2012. Aquatic hyphomycete communities associated with decomposing alder leaf litter in reference headwater streams of the Basque Country (northern Spain). Microb. Ecol. 64, 279-290.

Pérez, J., Martínez, A., Descals, E., Pozo, J., 2018. Responses of aquatic hyphomycetes to temperature and nutrient availability: a cross-transplantation experiment. Microb. Ecol. 76, 328-339.

Pinheiro, J., Bates, D., DebRoy, S., Sarkar, D., Team, R.C., 2009. nlme: linear and nonlinear mixed effects models. R package version 3, 96.

Rasmussen, J.J., Monberg, R.J., Baattrup-Pedersen, A., Cedergreen, N., WibergLarsen, P., Strobel, B., Kronvang, B., 2012. Effects of a triazole fungicide and a pyrethroid insecticide on the decomposition of leaves in the presence or absence of macroinvertebrate shredders. Aquat. Toxicol. 118-119, 54-61.

Rasmussen, J.J., Wiberg-Larsen, P., Baattrup-Pedersen, A., Monberg, R.J., Kronvang, B., 2012. Impacts of pesticides and natural stressors on leaf litter decomposition in agricultural streams. Sci. Total Environ. 416, 148-155.

Rossi, F., Pesce, S., Mallet, C., Margoum, C., Chaumot, A., Masson, M., Artigas, J., 2018. Interactive effects of pesticides and nutrients on microbial communities responsible of litter decomposition in streams. Front. Microbiol. 9, 2437.

R Core Team, 2019. R: A Language and Environment for Statistical Computing, 3.6. R Foundation for Statistical Computing, Vienna, Austria, 0.

Seena, S., Monroy, S., 2016. Preliminary insights into the evolutionary relationships of aquatic hyphomycetes and endophytic fungi. Fungal Ecology 19, 128-134.

Sigler, W.V., Turco, R.F., 2002. The impact of chlorothalonil application on soil bacterial and fungal populations as assessed by denaturing gradient gel electrophoresis. Appl. Soil Ecol. 21, 107-118. 
Sridhar, K.R., Krauss, G., Bärlocher, F., Raviraja, N.S., Wennrich, R., Baumbach, R., Krauss, G.J., 2001. Decomposition of alder leaves in two heavy metal- polluted streams in central Germany. Aquat. Microb. Ecol. 26, 73-80.

Steyna, M., Oberholstera, P.J., Bothab, A.M., Genthea, B., van den Heever-Kriekc, P.E., Weyersd, C.C., 2019. Treated acid mine drainage and stream recovery: Downstream impacts on benthic macroinvertebrate communities in relation to multispecies toxicity bioassays. J. Environ. Manag. 235, 377-388.

Swift, M.C., Smucker, R.A., Cummins, K.W., 1988. Effects of Dimilin on freshwater litter decomposition. Environ. Toxicol. Chem. 7, 161-166.

Tachet, H., Bournaud, M., Richoux, P., Usseglio-Polatera, P., 2000. Invertébrés D’eau Douce: Systématique, Biologie, Écologie. CNRS éditions, Paris.

Tonin, A.M., Boyero, L., Monroy, S., Basaguren, A., Pérez, J., Pearson, R.G., Cardinale, B. J., Gonçalves, J.F.J., Pozo, J., 2017. Stream nitrogen concentration, but not plant Nfixing capacity, modulates litter diversity effects on decomposition. Funct. Ecol. 31, $1471-1481$.

Tonin, A.M., Pozo, J., Monroy, S., Basaguren, A., Pérez, J., Goncalves Jr., J.F. Pearson, R., Cardinale, B.J., Boyero, L., 2018. Interactions between large and small detritivores influence how biodiversity impacts litter decomposition. J. Anim. Ecol. $87,1465-1474$.

Vannote, R.L., Minshall, G.W., Cummins, K.W., Sedell, J.R., Cushing, C.E., 1980. The river continuum concept. Can. J. Fish. Aquat. Sci. 37, 130-137.

Vigneron, A., Geffard, O., Queau, H., Francois, A., Chaumot, A., 2019. Nongenetic inheritance of increased $\mathrm{Cd}$ tolerance in a field Gammarus fossarum population: parental exposure steers offspring sensitivity. Aquat. Toxicol. 209, 91-98.

Wallace, J., Eggert, S., Meyer, J., Webster, J., 1997. Multiple trophic levels of a forest stream linked to terrestrial litter inputs. Science 277, 102-104.
Woodward, G., Gessner, M.O., Giller, P.S., Gullis, V., Hladyz, H., Lecerf, A., Malmqvist, B., McKie, B.G., Tiegs, S.D., Cariss, H., Dobson, M., Elosegi, A., Ferreira, V., Graça, M.A.S., Fleituch, T., Lacoursière, J.O., Nistorescu, M., Pozo, J., Risnoveanu, G., Schindler, M., Vadineanu, A., Vought, L.M., Chauvet, E., 2012. Continental-scale effects of nutrient pollution on stream ecosystem functioning. Science 336, 1438-1440.

Zubrod, J.P., Bundschuh, M., Feckler, A., Englert, D., Schulz, R., 2011. Ecotoxicological impact of the fungicide tebuconazole on an aquatic decomposer-detritivore system. Environ. Toxicol. Chem. 30, 2718-2724.

Zubrod, J.P., Baudy, P., Schulz, R., Bundschuh, M., 2014. Effects of current-use fungicides and their mixtures on the feeding and survival of the key shredder Gammarus fossarum. Aquat. Toxicol. 150, 133-143.

Zubrod, J.P., Englert, D., Feckler, A., Koksharova, N., Konschak, M., Bundschuh, R. Schnetzer, N., Englert, K., Schulz, R., Bundschuh, M., 2015a. Does the current fungicide risk assessment provide sufficient protection for key drivers in aquatic ecosystem functioning? Environ. Sci. Technol. 49, 1173-1181.

Zubrod, J.P., Englert, D., Wolfram, J., Wallace, D., Schnetzer, N., Baudy, P., Konschak, M., Schulz, R., Bundschuh, M., 2015b. Waterborne toxicity and dietrelated effects of fungicides in the key leaf shredder Gammarus fossarum (Crustacea: Amphipoda). Aquat. Toxicol. 169, 105-112.

Zubrod, J.P., Englert, D., Wolfram, J., Rosenfeldt, R.R., Feckler, A., Bundschuh, R., Seitz, F., Konschak, M., Baudy, P., Luderwald, S., Fink, P., Lorke, A., Schulz, R., Bundschuh, M., 2017. Long-term effects of fungicides on leaf-associated microorganisms and shredder populations-an artificial stream study. Environ. Toxicol. Chem. 36, 2178-2189. 